\title{
Oxidation of Carbon/Carbon through Coating Cracks
}

\author{
N. S. Jacobson ${ }^{\text {a }}$, D. J. Roth ${ }^{\mathrm{a}}$, R. W. Rauser ${ }^{\mathrm{b}}$, J. D. Cawley ${ }^{\mathrm{c}}$, and D. M. Curry ${ }^{\mathrm{d}}$ \\ a NASA Glenn Research Center, Cleveland, Ohio 44135, USA \\ ${ }^{\mathrm{b}}$ University of Toledo, Toledo, Ohio 43606, USA \\ ${ }^{\mathrm{c}}$ Department of Materials Science, CWRU, Cleveland, Ohio 44106, USA \\ ${ }^{\mathrm{d}}$ The Boeing Company, Houston, Texas 77058, USA
}

\begin{abstract}
Reinforced carbon/carbon (RCC) is used to protect the wing leading edge and nose cap of the Space Shuttle Orbiter on re-entry. It is composed of a lay-up of carbon/carbon fabric protected by a $\mathrm{SiC}$ conversion coating. Due to the thermal expansion mismatch of the carbon/carbon and the $\mathrm{SiC}$, the $\mathrm{SiC}$ cracks on cool-down from the processing temperature. The cracks act as pathways for oxidation of the carbon/carbon. A model for the diffusion controlled oxidation of carbon/carbon through machined slots and cracks is developed and compared to laboratory experiments. A symmetric cylindrical oxidation cavity develops under the slots, confirming diffusion control. Comparison of cross sectional dimensions as a function of oxidation time shows good agreement with the model. A second set of oxidation experiments was done with samples with only the natural craze cracks, using weight loss as an index of oxidation. The agreement of these rates with the model is quite reasonable.
\end{abstract}

\section{Introduction}

The wing leading edge and nose cap of the Space Shuttle Orbiter are the hottest parts of the vehicle on reentry. These are constructed of a reinforced carbon/carbon (RCC) in order to take temperatures of up to $1650^{\circ} \mathrm{C}$ for short periods of time (1). The carbon/carbon is composed of a two-dimensional lay-up of carbon/carbon fabric infiltrated with a liquid carbon precursor to fill porosity. Oxidation protection is achieved with a SiC conversion coating and two types of glass sealants. First the entire piece is infiltrated with tetra-ethyl orthosilicate (TEOS), which decomposes to silica on a mild heat treatment. Then the outer surfaces are painted with a sodium silicate based sealant. This sealant becomes liquid at high temperatures and fills any open cracks which limits oxidation. In order to clearly observe oxidative degradation, the material studied here did not have the outer silicate sealant. It did, however, have the TEOS treatment, which had a relatively minor effect on oxidation. A schematic of this material is given in Figure 1.

The coefficient of thermal expansion (CTE) of carbon-carbon ( 1 ppm/K) (2) is not wellmatched to that of $\mathrm{SiC}(\sim 5-6 \mathrm{ppm} / \mathrm{K})(3)$. Upon cool-down from the application temperature of the $\mathrm{SiC}$ coating, this leads to tensile stresses within the coating. At some point the coating cracks to relieve these stresses. Ideally these cracks should close on reheating, but in practice they do not. Hence they provide paths for oxygen inward and carbonaceous oxidation products outward, which thus allows carbon oxidation. This cracking and subsequent consumption of carbon is shown schematically in Figure 1. A micrograph is shown of this type of attack is shown in Figure 2. 


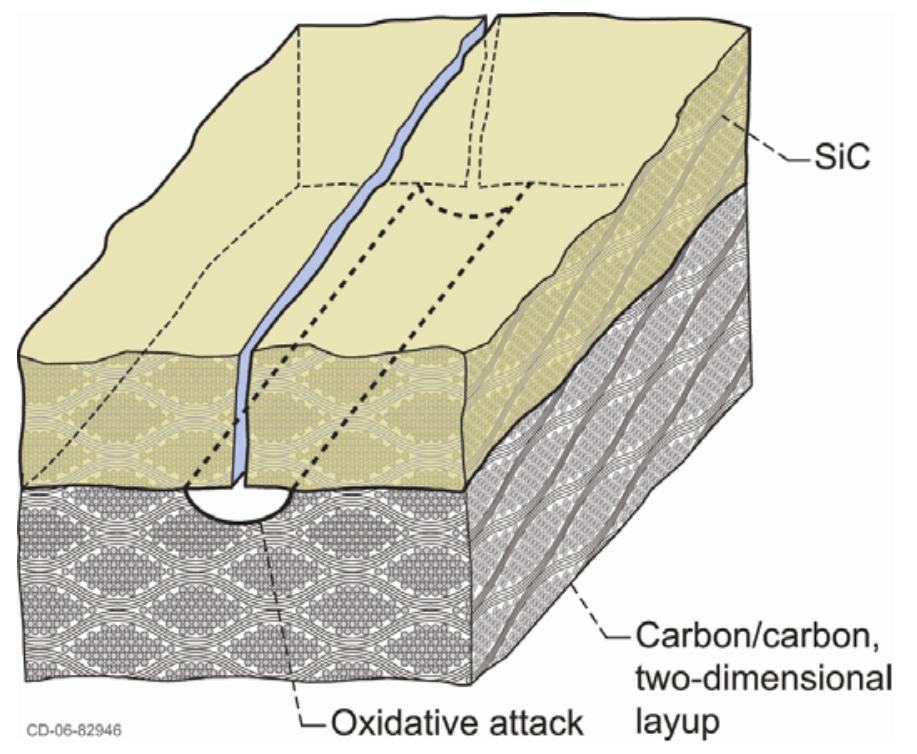

Figure 1. Schematic of RCC material used in this study._Reprinted from Reference (13) with permission from Elsevier.

The purpose of this study is to develop a mathematical model of this type of oxidation. Laboratory experiments to verify this model were done with two types of specimens. The first type of specimens were RCC with machined slots of well-defined geometry. These slots simulated craze cracks of accurately known dimensions. The second type of specimens were RCC with natural cracks. Prior to each experiment the slots or craze cracks were thoroughly characterized. Oxidation damage was evaluated with one of three techniques (a) Cross sections (b) Total weight loss and (c) X-ray computed tomography (X-ray CT). The results were then compared to the model.

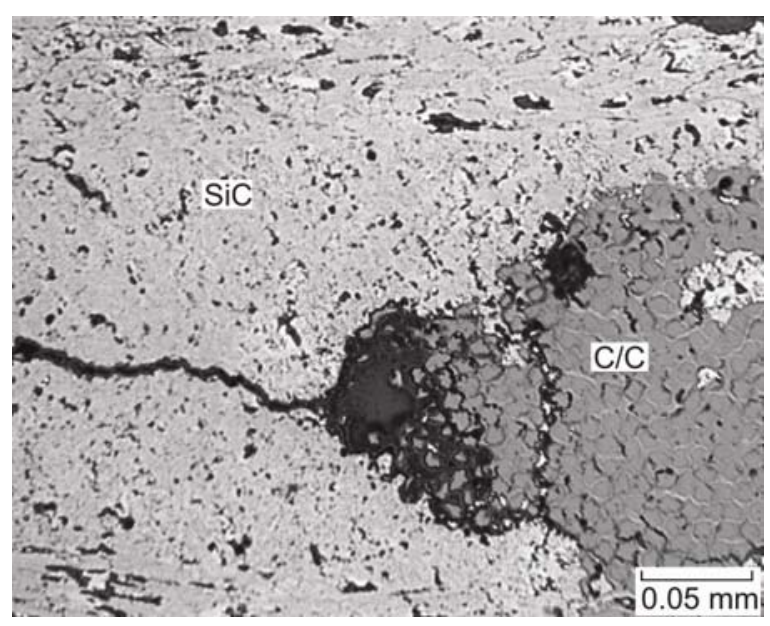

Figure 2. Oxidation cavity below a craze crack in RCC. Oxidation in air at $1100^{\circ} \mathrm{C}$ and $0.0066 \mathrm{~atm}$ (669 Pa) for $1 \mathrm{hr}$. Reprinted from Reference (13) with permission from Elsevier. 


\section{Oxidation Modeling}

The oxidation of carbon is one of the most intensively studied chemical reactions and there is a large amount of literature on it. The current study is focused on diffusion controlled oxidation of carbon/carbon. Figure 5 is an Arrhenius plot for oxidation of the RCC fabric in flowing air. The diffusion control regime is above $\sim 800^{\circ} \mathrm{C}$. The symmetric oxidation cavities observed below the machined slots, as shown in Figures 6 and 7 , further support diffusion control.

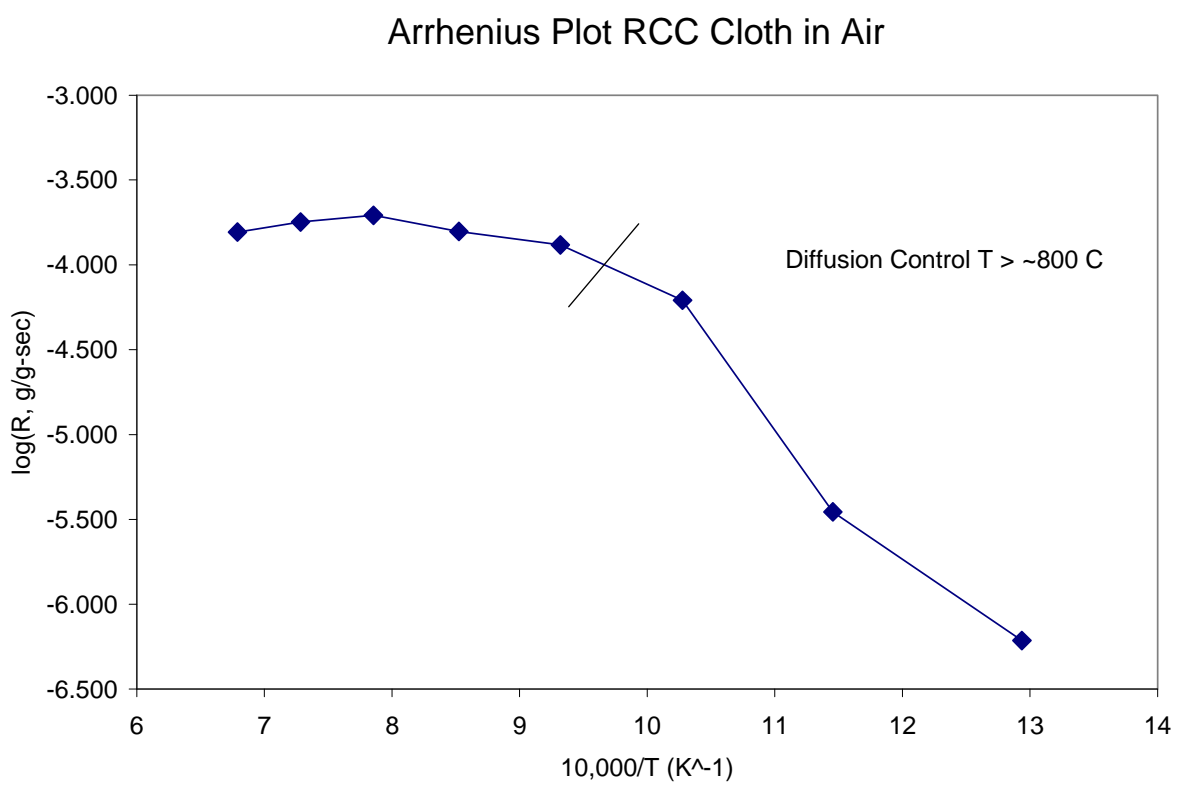

Figure 5. Arrhenius plot of carbon/carbon fabric oxidation in air.

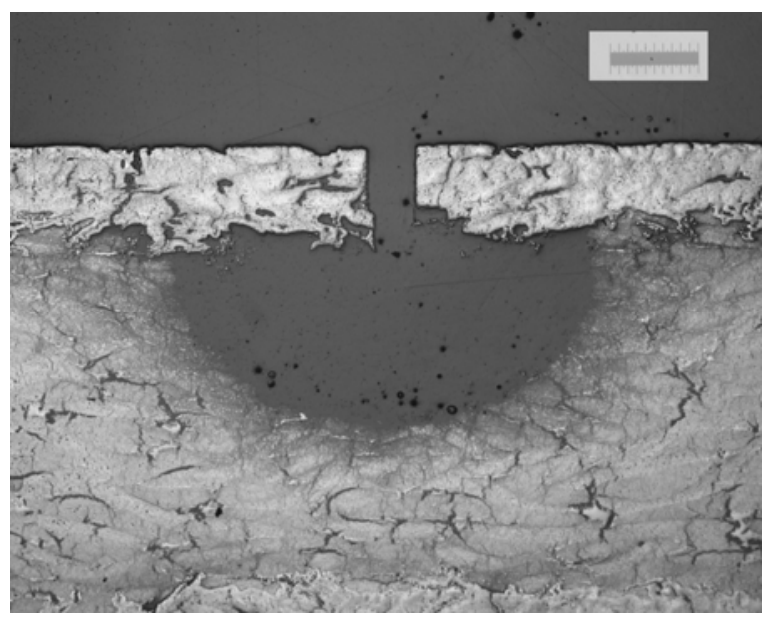

Figure 6. Cross section of oxidation trough from oxidation through a slot. Oxidation in air at $1200^{\circ} \mathrm{C}$ and $1 \mathrm{~atm}(0.1 \mathrm{MPa})$ for $2.5 \mathrm{hr}$. Bar is $1 \mathrm{~mm}$. 


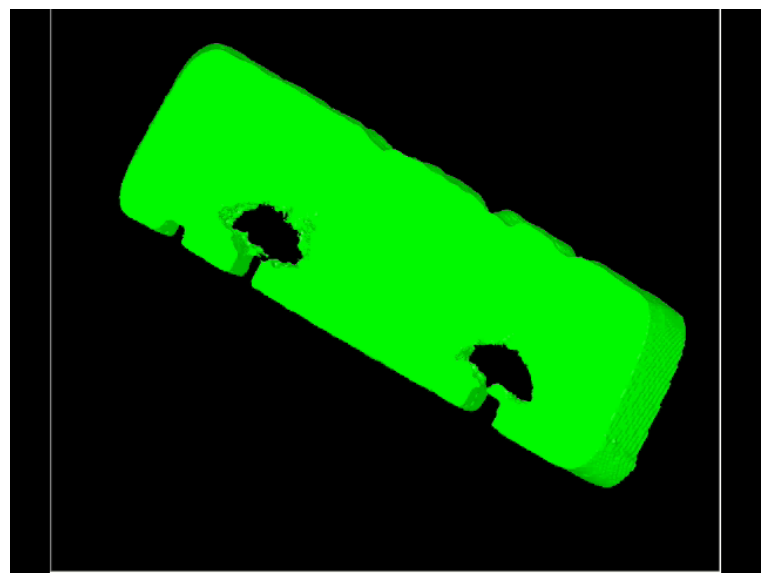

Figure 7. Oxidation cavity in RCC through a slot. Three dimensional reconstruction from X-ray CT. Oxidation in air at $1200^{\circ} \mathrm{C}$ at 1 atm $(0.1 \mathrm{MPa})$ for $0.5 \mathrm{hr}$. Reprinted from Reference (13) with permission from Elsevier.

In low oxygen potentials, carbon oxidation leads to $\mathrm{CO}(\mathrm{g})$. However $\mathrm{CO}(\mathrm{g})$ and $\mathrm{O}_{2}(\mathrm{~g})$ are thermodynamically incompatible. They will react to form the more thermochemically stable $\mathrm{CO}_{2}(\mathrm{~g})$. For this reason, oxidation of carbon is generally treated in two steps:

At the carbon/gas interface: $\mathrm{C}(\mathrm{s})+\mathrm{CO}_{2}(\mathrm{~g})=2 \mathrm{CO}(\mathrm{g})$

At some distance away from the carbon/gas interface: $\mathrm{CO}(\mathrm{g})+1 / 2 \mathrm{O}_{2}(\mathrm{~g})=\mathrm{CO}_{2}(\mathrm{~g})$

The net reaction is the oxidation of $\mathrm{C}$ to $\mathrm{CO}(\mathrm{g})$, but separation to these two steps avoids the $\mathrm{CO} / \mathrm{O}_{2}$ incompatibility problem. Further, combustion studies of carbon show this secondary reaction front some distance away from the solid surface (4).

There are several studies in the literature of carbon oxidation through channels (slots or cracks) in an inert matrix (5-13). The equations for this type of oxidation are well established and have been presented by these authors. In this treatment, we include diffusion not only through the $\mathrm{SiC}$ channel, but also through the growing oxidation cavity. A schematic of this process is shown in Figure 8. 


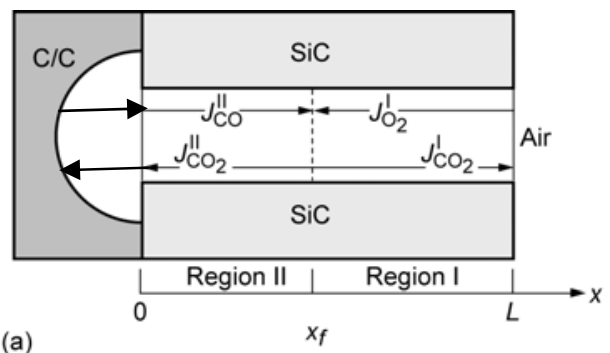

(a)
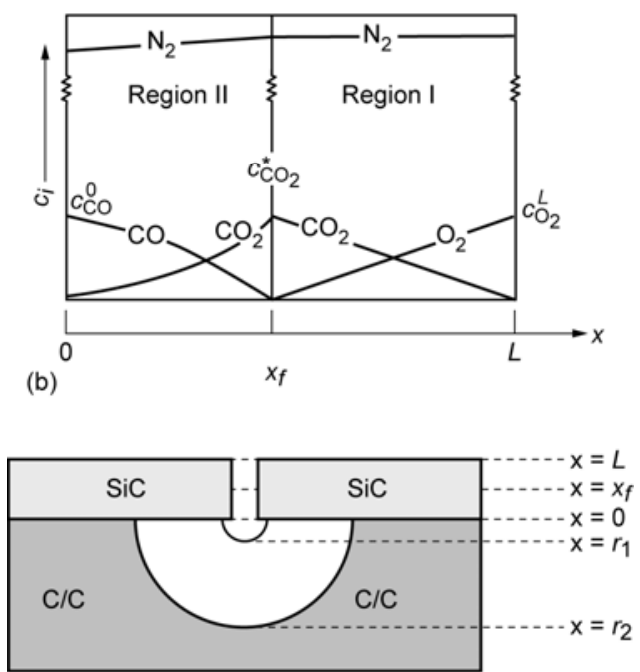

(c)

Figure 8. Schematic of oxidation process. (a) Opposing fluxes of gaseous products and reactants and growing cavity (b) Relative concentrations in the channel (c) Schematic of channel and cavity showing designation of boundary conditions in the equations.

Reprinted from Reference (13) with permission from Elsevier.

Details of the equations are given elsewhere (13). Equations are set up for the channel in rectangular coordinates and the growing cavity in polar coordinates. The equations for the flux in the channel are written as:

$$
J_{i}=D_{i}^{\text {eff }}\left(\frac{\partial c_{i}}{\partial x}\right)+\mathrm{v}_{i}^{a v e} c_{i}
$$

Here $J_{i}$ is the flux of species $\mathrm{I}, D_{i}^{\text {eff }}$ is the effective diffusion coefficient, $c_{i}$ is the concentration of species $i, x$ is the distance along the channel, and $\mathrm{v}_{i}^{\text {ave }}$ is the average velocity of species $i$. The first term in this expression is the diffusive flux and the second term is the convective flux. The convective term can be simplified since: 


$$
\mathrm{v}_{i}^{\text {ave }}=\frac{\sum_{i} c_{i} v_{i}}{\sum_{i} c_{i}}=\frac{\sum_{i} J_{i}}{C_{T}}
$$

Here $c_{T}$ is the total of the concentration of species $i$. The boundary conditions are as follows:

At the base of the channel: $x=0: \quad c_{\mathrm{CO}}=c_{\mathrm{CO}^{\circ}}^{0} \quad c_{\mathrm{CO}_{2}}=c_{\mathrm{CO}_{2}}^{0}$

At the site of reaction [2]: $x=x_{f}: \quad c_{\mathrm{CO}_{2}}=c_{\mathrm{CO}_{2}}^{*} \quad c_{\mathrm{O}_{2}}=c_{\mathrm{CO}}=0$

At the mouth of the channel: $x=L: \quad c_{\mathrm{O}_{2}}=c_{\mathrm{O}_{2}}^{L} \quad c_{\mathrm{CO}_{2}}=0$

As discussed, these equations have been solved analytically by several authors (6-12). The first step is to derive an expression for $x_{f} / L$. Then an expression for the flux of $\mathrm{CO}_{2}$ is developed, which related to carbon consumption.

In this study, the equations are further extended by added the fluxes in the growing cavity. As noted, these are best written in polar coordinates.

$$
J_{\mathrm{CO}_{2}}^{\mathrm{tr}} A^{\prime}=-D_{\mathrm{CO}_{2}} A^{\prime}\left(\frac{\partial c_{\mathrm{CO}_{2}}}{\partial r}\right)-\frac{A^{\prime} c_{\mathrm{CO}_{2}} J_{\mathrm{CO}_{2}}^{t r}}{c_{T}}
$$

Here $J_{\mathrm{CO}_{2}}^{t r}$ is the flux of $\mathrm{CO}_{2}$ in the growing 'trough' (see Figure 7), $A$ ' is the area of exposed carbon for oxidation, and $r$ is the radius of the trough. The flux of $\mathrm{CO}_{2}$ at the base of the channel is then equated to the flux of $\mathrm{CO}_{2}$ entering the trough. The resultant equation is solved for the concentration of $\mathrm{CO}_{2}$ at $\mathrm{r}_{1}, c_{\mathrm{CO}_{2}}^{r_{1}}$, and this quantity is then put back the integrated form of equation [6]. Assuming a reaction probability of one, the flux of $\mathrm{CO}_{2}$ can be related to both a radius of the growing trough and a weight loss. It is not possible to solve for trough radius or weight loss as a function of time. Nonetheless, the reverse can be done and the following equations are used to generate oxidation kinetics. The time, $t$, as function of trough radius, $r_{2}$, is given by:

$$
t=\frac{M_{\mathrm{CO}_{2}}}{M_{\mathrm{C}}} \frac{\rho}{D_{\mathrm{CO}_{2}} c_{\mathrm{CO}_{2}}^{*}}\left[\begin{array}{l}
\frac{r_{2}^{2}}{2} \ln \left(r_{2}\right)-\frac{r_{2}^{2}}{4}-\frac{r_{2}^{2}}{2} \ln r_{1}+\frac{r_{2}^{2}}{2}\left(\frac{\pi x_{f}\left(c_{T}+c_{\mathrm{CO}_{2}}^{*}\right)}{r_{1} c_{T}}\right)+\frac{r_{1}^{2}}{4}- \\
\frac{r_{1}^{2}}{2}\left(\frac{\pi x_{f}\left(c_{T}+c_{\mathrm{CO}_{2}}^{*}\right)}{r_{1} c_{T}}\right)
\end{array}\right]
$$

The time, $t$, as a function of weight loss, $W$, is given by: 
$t=\frac{M_{C O_{2}}}{M_{C}} \frac{\rho}{D_{\mathrm{CO}_{2}} c_{C O_{2}}^{*}}\left[\frac{\left(\sqrt{\frac{2 W}{\pi \rho l}}+r_{1}\right)^{2}}{2} \ln \left(\sqrt{\frac{2 W}{\pi \rho l}}+r_{1}\right)-\frac{\left(\sqrt{\frac{2 W}{\pi \rho l}}+r_{1}\right)^{2}}{4}-\frac{\left(\sqrt{\frac{2 W}{\pi \rho l}}+r_{1}\right)^{2}}{2} \ln r_{1}\right]$

[8]

Here $M_{i}$ is the molecular weight of species $I, D_{i}$ is the diffusivity of species $i, c_{\mathrm{CO}_{2}}^{*}$ is the concentration of $\mathrm{CO}_{2}$ at position $x_{f}, \rho$ is the density of carbon/carbon, $l$ is the crack length, $c_{T}$ is the total concentration of gaseous species in the crack, and $r_{1}$ is shown in Figure 8(c). Although equation [8] is complex, it was found that the linear terms dominate and a linear weight loss term can be derived for comparison to experiment.

An important consideration is the change of the channel geometry with temperature. Two possible changes can occur. For the craze cracks, the cracks should ideally expand and close as temperature increases. Clearly this does not occur, as oxidation is still observed (Figure 2). So for the purposes of this approximation, the room temperature crack width is used. The second consideration is crack wall oxidation. Electron microscope observations indicated only very thin oxidation films are formed and most of the oxidation is internal oxidation of the porous $\mathrm{SiC}$ coating [13]. For this reason, oxidation crack width changes due to oxidation were neglected.

\section{Comparison of Laboratory Results to Model}

\section{Machined Slots}

The first set of experiments was done with $1.9 \mathrm{~cm}$ diameter disc of RCC with a SiC coating on all sides and a TEOS treatment. Slots of 0.25, 0.50, 0.76, and $1.02 \mathrm{~mm}$ width were made to the $\mathrm{SiC} /$ carbon-carbon interface. Oxidation treatments were done at $1200^{\circ} \mathrm{C}$ in a box furnace with static laboratory air. Oxidation damage was assessed in two ways. All specimens were weighed before and after exposure. Some were sectioned as shown in Figure 6. Imaging analysis software was used to measure to measure the cross sectional area. The areas were approximated as a semi-circle and the radii extracted.

Figure 8 compares the measured radii to the model for two different slot widths. The solid line shows the model for diffusion only in the slot, ignoring the growing oxidation void. The dashed line shows the model for the coupled equations of diffusion in the slot and the void (equation [7]). Agreement with this model is very good. 

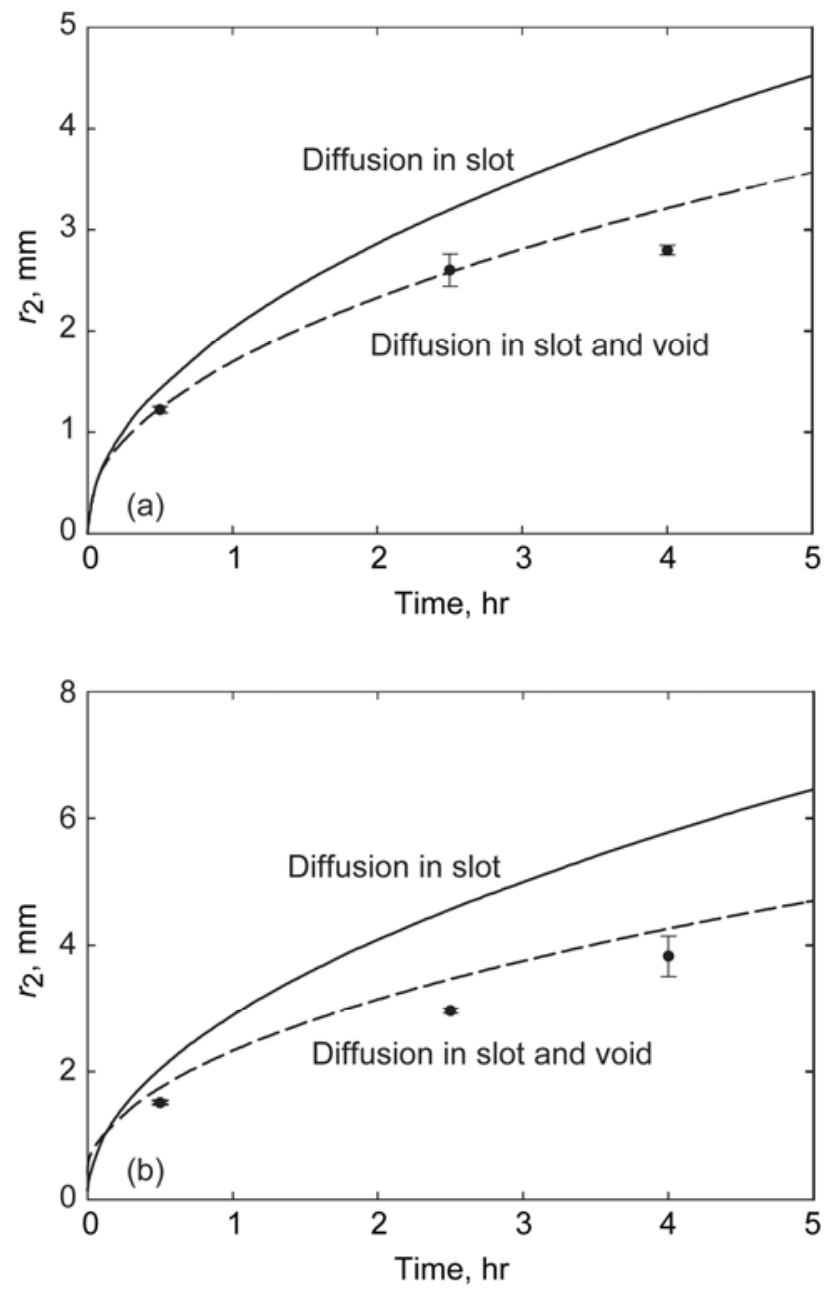

Figure 9

Figure 9. Comparison of experiment to model for (a) 0.53 width slot and (b) $1.02 \mathrm{~mm}$ width slot. Oxidation in air at 1 atm $(0.1 \mathrm{MPa})$ at $1200^{\circ} \mathrm{C}$. Reprinted from Reference (13) with permission from Elsevier.

A second set of experiments was done with machined slots of various width, using total weight loss as an index of oxidation. Oxidation rates were measured in a box furnace by removing the slotted specimens every $0.5 \mathrm{hr}$ for a weight measurement. After an initial period of weight gain, which was attributed to $\mathrm{SiC}$ oxidation, the specimens lost weight linearly. This weight loss is reported in Table I. Note that in each case the measured values are higher than the calculated values. This is very likely due to additional contributions from oxidation through the craze cracks in the discs.

\begin{tabular}{|c|c|c|c|}
\hline Slot width, mm & Slot length, mm & $\begin{array}{l}\text { Measured weight loss } \\
\text { mg/mm }{ }^{2}-h r\end{array}$ & $\begin{array}{c}\text { Calculated weight loss } \\
\mathrm{mg} / \mathrm{mm}^{2}-\mathrm{hr}\end{array}$ \\
\hline $0.484 \pm 0.062$ & $8.177 \pm 0.923$ & $34 \pm 6$ & 11.2 \\
\hline $0.312 \pm 0.033$ & $8.284 \pm 0.63$ & $48 \pm 6$ & 12.5 \\
\hline $0.560 \pm 0.013$ & $7.094 \pm 0.132$ & $48 \pm 1$ & 10.8 \\
\hline $0.466 \pm 0.04$ & $7.114 \pm 0.019$ & $43 \pm 5$ & 11.4 \\
\hline $1.116 \pm 0.024$ & $7.602 \pm 0.101$ & $18 \pm 1$ & 8.6 \\
\hline $0.963 \pm 0.004$ & $7.624 \pm 0.0 .39$ & $21 \pm 1$ & 9.1 \\
\hline
\end{tabular}




\section{Natural Craze Cracks}

The second set of experiments were done with $1.9 \mathrm{~cm}$ diameter disc of RCC with a $\mathrm{SiC}$ coating on all sides and a TEOS treatment. No slots were machined in these and oxidation occurred only through the natural craze cracks. The crack pattern was clearly revealed in a specimen by polishing a few hundred microns off the surface. This is shown in Figure 10 below. From this photo as well as cross sectional views, crack parameters such as crack length/unit area, crack width, and coating thickness were measured. These were used in the model.

Oxidation exposures were done in a thermogravimetric apparatus (TGA) with flowing air. These continuous weight change measurements revealed a weight gain for the first 1 hr or so of the oxidation run and then a smooth linear weight loss. This weight loss was determined and reported in Table II.

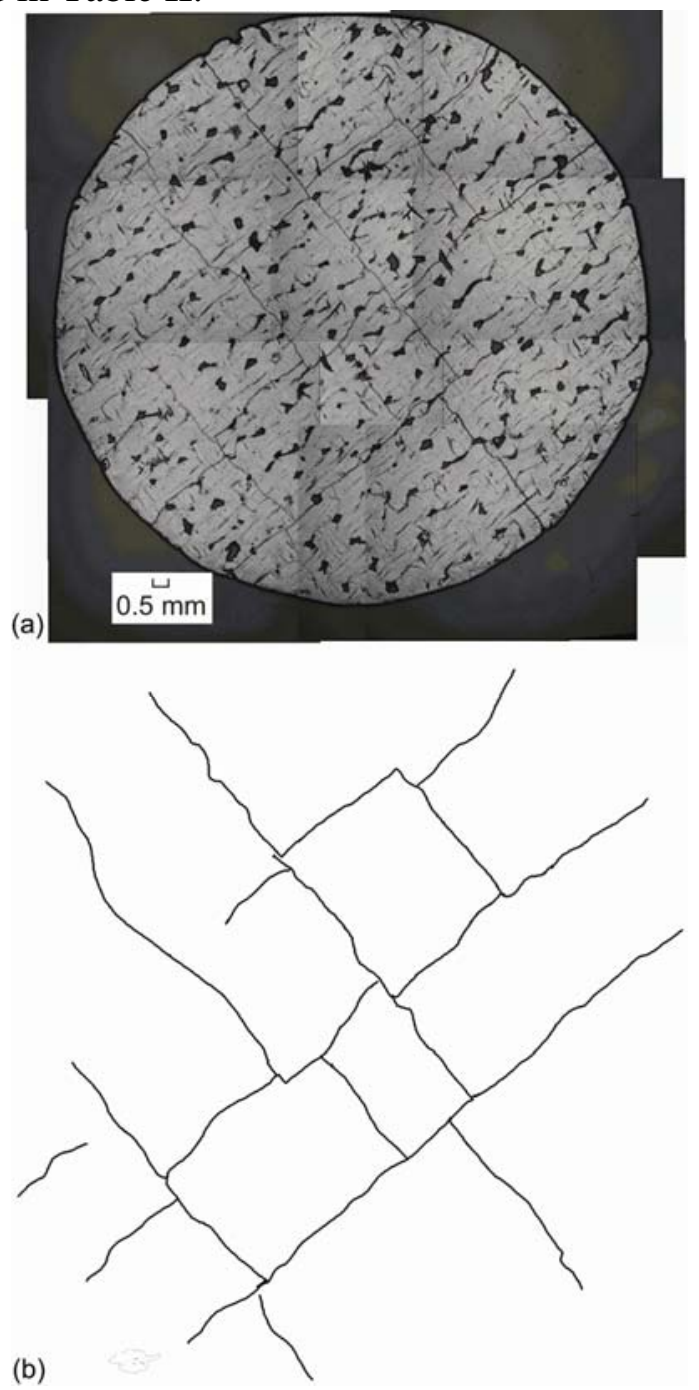

Figure 10. (a) RCC sample polished to reveal crack pattern (b) 'Skeleton' trace of that crack pattern. Reprinted from Reference (13) with permission from Elsevier. 
The results from the model are shown in Table II. Neither the craze cracks or the resultant oxidation cavities were of the uniform geometries observed with the machined cracks. A 'tortuosity' factor was not used to account for this non-ideality. Nontheless the agreement between the model and the experiments is quite reasonable suggesting the deviations from non-ideality are not great and/or tend to cancel each other.

\begin{tabular}{|c|c|c|c|}
\hline Temperature, ${ }^{\circ} \mathrm{C}$ & $\begin{array}{l}\text { Area of Carbon } \\
\text { exposed craze cracks, } \\
\text { mm }^{2}\end{array}$ & $\begin{array}{l}\text { Measured weight loss } \\
\mathrm{mg} / \mathrm{mm}^{2}-\mathrm{hr}\end{array}$ & $\begin{array}{c}\text { Calculated weight loss } \\
\mathrm{mg} / \mathrm{mm}^{2}-\mathrm{hr}\end{array}$ \\
\hline 1000 & $3.60 \pm 0.923$ & $26 \pm 7$ & 14.7 \\
\hline 1100 & $3.96 \pm 0.63$ & $21 \pm 6$ & 13.6 \\
\hline 1200 & $3.99 \pm 0.132$ & $30 \pm 8$ & 16.1 \\
\hline 1300 & $3.97 \pm 0.019$ & $41 \pm 9$ & 16.8 \\
\hline
\end{tabular}

\section{Summary and Conclusions}

Oxidation of SiC-protected carbon/carbon was studied in the temperature range 1000$1300^{\circ} \mathrm{C}$. The $\mathrm{SiC}$ coating cracks due to the thermal expansion mismatch between the $\mathrm{SiC}$ and the carbon/carbon. These cracks provide pathways for oxygen inward and carbon oxidation products outward. In this temperature regime, oxidation of carbon is gas-phase diffusion controlled. A model is developed for this type of oxidation, based on the two step oxidation of carbon and diffusion in both the SiC channel and growing oxidation cavity in the carbon/carbon substrate. Experiments were done on RCC with machined slots and RCC with only natural craze cracks. For the samples with machined slots, oxidation was measured with cross sectional areas of the cavities below the slots. Agreement with the model was very good. Oxidation for these samples was also measured with net weight loss and the model tended to under-predict, very likely due to contributions of additional oxidation through the craze cracks. The samples with craze cracks only were thoroughly characterized and oxidation was measured with weight loss. Agreement with the model was quite reasonable.

\section{Acknowledgments}

It is a pleasure to acknowledge the many helpful discussions of this work with various individuals. These include R. A. Rapp, G. Wang, and X. Zheng formerly of the Ohio State University; T. Parathasarathy of UES, Inc.; and E. Opila, C. Spruckler, and L. Ghosn of the NASA Glenn Research Center.

\section{References}

1. D. M. Curry, H. C. Scott, and C. N. Webster, in $24^{\text {th }}$ National SAMPE Symposium and Exhibition, Vol. 24-2, SAMPE, San Francisco, CA, (1979)

2. T. Ullmann, M. Shmücker, H. Hald, R. Henne, and H. Schneider, in Proceedings of 8th International Symposium on Materials in a Space Environment, Archachon, Frankreich, (2000).

3. Y.S. Touloukian, R.K. Kirby, R.E. Taylor, and T.Y.R. Lee, in Thermal Expansion Nonmetallic Solids, p. 873, IFI/Plenum, New York, NY (1977).

4. A. M. Kanury, Introduction to Combustion Phenomena, p. 204, Gordon and Breach, New York, (1982). 
5. J.E. Medford, in 10th AIAA Thermophysics Conference, AIAA, Denver, CO, (1975).

6. J. Bernstein and T.B. Koger, J. Electrochem. Soc. 1352086 (1988).

7. E.L. Courtright, J.T. Prater, G.R. Holcomb, G.R. St. Pierre, and R.A. Rapp, Oxid. Met. 36, 423 (1991).

8. L. Filipuzzi, G. Camus, R. Naslain, and J. Thebault, J. Am. Ceram. Soc. 77, 459 (1994).

9. L. Filipuzzi and R. Naslain, J. Am. Ceram. Soc. 77, 467 (1994).

10. G.R. Holcomb, Corrosion 52, 531 (1996).

11. A. J. Eckel, J. D. Cawley, and T. A. Parthasarathy, J. Am. Ceram. Soc. 78, 972 (1995).

12. N.S. Jacobson, T.A. Leonhardt, D.M. Curry, and R.A. Rapp, Carbon 37, 411 (1999).

13. N.S. Jacobson, D. J. Roth, R. W. Rauser, J. D. Cawley, and D. M. Curry, Surf \& Coat. Tech. 203, 372 (2008). 